\title{
Multi Voltage Multi Circuit Transmission Tower Design to Reduce Right of Way
}

\author{
Yasaswini ${ }^{1 *}$, S. V. N. L. Lalitha ${ }^{1}$ and Shefali Talati ${ }^{2}$ \\ 'Electrical and Electronics Engineering, K L University, Vijayawada - 522502, Andhra Pradesh, India; yasaswini.al- \\ lada@gmail.com, lalitha@kluniversity.in \\ ²Electrical Research and Development Association, Vadodara - 390010, Gujarat, India; shefali.talati@erda.org
}

\begin{abstract}
Objectives: To design multi-voltage multi-circuit transmission tower to reduce right of way (RoW). Methods/Statistical Analysis: In order to reduce right of way structural optimization and electro-magnetic analysis should be carried out. Structural optimization includes various factors like conductor configuration, cross arm arrangement, wind loadings. The tower is designed using Staad Pro and the structure is validated for various wind loadings and stresses. Electro-static and magneto-static fields around the tower are analyzed and are brought down to limits by choosing optimal phase sequence. This analysis is carried out using Ansoft Maxwell. Findings: The designed structure withstands all the permissible stresses. Electro-static and magneto-static fields around the designed tower are found to be within the specified limits specified by standards. This design is found to be cost effective with respect to right of way when a transmission line is considered. Application / Improvements: Narrow base width is considered which also aids in optimized right of way. This tower design can hold three voltages $(400 \mathrm{kV}, 220 \mathrm{kV}, 33 \mathrm{kV})$ and six circuits. The height of the tower is maintained in normal range by structural optimization.
\end{abstract}

Keywords: MVMCT, Narrow based Tower, Right of Way

\section{Introduction}

The cost of towers ranges from one fourth to half of the transmission line cost and hence optimum design gives reasonable savings. Consequently, transmission line towers should be designed for structural and electrical requirements for a safe and economical design. Right Of Way (ROW) is the right to claim a land strip by various Electrical utilities for erection, operation, maintenance and repair the transmission line facilities. Its width relies on the line voltage rating, height of the structure, electromagnetic fields intensity and structure of the tower. Old transmission lines can be dismantled or renovated by configuring new MVMCT lines using same old ROW with tolerable broadening so that transmission line of higher voltage rating of MVMCT line can transmit power between major substations while that of lower voltage line can transmit power between smaller substations. In the literature some of the tower designs include optimiza- tion of the geometry, electromagnetic field reduction, etc. which are discussed.

A few solutions for reduction of electric and magnetic field emissions caused by the overhead power lines are discussed ${ }^{1}$. Calculations carried out for existing high voltage $400 \mathrm{kV}$ overhead lines in Slovenia show that the emissions of electric and magnetic field at the border of overhead line ROW could be too high. The analysis is carried out for single voltage but it would be economical if many voltages are also incorporated in the design.

Structural optimization of a typical $132-\mathrm{kV}$ double circuit transmission-line tower with respect to configuration and different materials as variable parameters, the tower is modeled and analyzed using STAAD-PRO and ANSYS softwares ${ }^{2}$. A number of experimental configurations of the tower are obtained by increasing the base width of the tower and also by decreasing the bracing patterns below the waist of the tower. In this paper only tower optimiza-

${ }^{*}$ Author for correspondence 
tion is discussed but ROW is not reduced which may not be economical when land issues are concerned.

Narrow base multi circuit tower is analyzed for 200 KV using STADD.PRO ${ }^{3}$. The choice of tower is made based on the available right of way. Narrow base tower is considered for Mumbai area so as to meet ROW constraint. In this only a single voltage is considered which may give very less transmission capacity when compared to multi voltages.

A comparative study of electromagnetic field distribution near ground ( $1.5 \mathrm{~m}$ above the ground) for $500 / 220 \mathrm{kV}$ dual voltage quadruple circuit transmission line of 3 typical tower types and 12 phase sequence arrangements are calculated, and from the comparison optimal phase sequence arrangement is found ${ }^{4}$. The sequences are given which may not ensure that row is also justified by the proposed sequence.

The electric and magnetic fields distribution under EHV transmission lines are analyzed using finite element analysis ${ }^{5}$. From these results, most reliable position of transmission lines is achieved on tower and the best phase line sequence with least electromagnetic field intensity in $500 \mathrm{kV} / 220 \mathrm{kV}$ dual voltage quadruple circuit transmission lines on same tower. The fields are less for the proposed sequence but it is not justified with geometry optimization which is the need of the hour.

Design optimization of $220 \mathrm{KV}$ and $110 \mathrm{KV}$ dual voltage multi circuit self-supporting lattice tower with narrow base is carried out ${ }^{6}$. Design and analysis are done using STAAD PRO. Only geometry is optimized but the corresponding fields are not calculated as the multi circuits are highly prone to electromagnetic fields due to interaction among themselves.

When considering all the limitations the proposed MVMCT would solve all the issues of a transmission tower according to the present needs. Due to technical and financial reasons, future electrical transmission towers need to adopt new design concepts by maximizing power delivery with confined ROW.

In this paper we are optimizing the tower geometry by adopting narrow base which is not only economical but also reduces the ROW width. Narrow based steel lattice transmission tower structure plays a vital role in its performance especially when there are eccentric loading conditions for higher altitude as compared to conventional tower.

The paper is organized as follows: General design concepts are presented in the second section. Proposed
MVMCT design is discussed in the third section. The results are included in the fourth section. The fifth section deals with the conclusion.

The following section deals with the general design concepts of a transmission tower as per Indian standards.

\section{General tower Design Concepts}

The basic tower designing steps are simplified and given below in a flow chart. Geometry of tower plays a crucial role in understanding the basic design concepts. Tower geometry includes the voltage level, base width, type, height, conductor configuration, type of conductors and number of circuits. The number of cross arms depends on the voltage level and number of circuits. ROW is the right to claim a land strip by various Electrical utilities for erection, operation, maintenance and repair the transmission line facilities. Its width relies on the line voltage rating, height of the structure, electromagnetic fields intensity and structure of the tower. ROW is fixed based on the tower geometry and Electromagnetic fields.

\subsection{Sag}

The power conductors sags because of its self-weight and the maximum sag is observed under maximum temperature and no wind condition. Sag and tension are calculated for various wind and temperature combinations as per IS 802 standard $^{7}$. Maximum sag value is also used to determine the height of a transmission tower.

\subsection{Height Determination}

Various factors that influence the height of the tower are:

1. Minimum permissible ground clearance (h1)

2. Maximum sag (h2)

3. Vertical spacing between phase conductors (h3)

4. Vertical clearance between top conductor and ground wire (h4)

Hence, the total height of the tower is given by

$\mathrm{H}=\mathrm{h} 1+\mathrm{h} 2+\mathrm{h} 3+\mathrm{h} 4$

When multi circuits are considered, circuit to circuit clearance will be added to the height of the tower accordingly

\subsection{Electrical Clearances}

The electrical clearances involve selection of minimum air gap clearances, to avoid distracting sources between 
live and earthed parts of the transmission line. All the minimum electrical clearances are maintained according to CBIP guidelines ${ }^{8}$.

\subsection{Wind Loadings}

The calculated loads as per the particular wind zone are applied to the tower structure. Loadings include selfweight, transverse loads, longitudinal loads, compression loads and tension loads. No deflection is observed in tower after applying these loads that are calculated as per standards ${ }^{9}$.The loadings determination is done using various inputs like design wind pressure, angle of deviation, design wind span, pressure due to wind on conductor and ground wire, type of ground wire, insulator strings, etc. All the members of the tower are applied with the corresponding loading combinations.

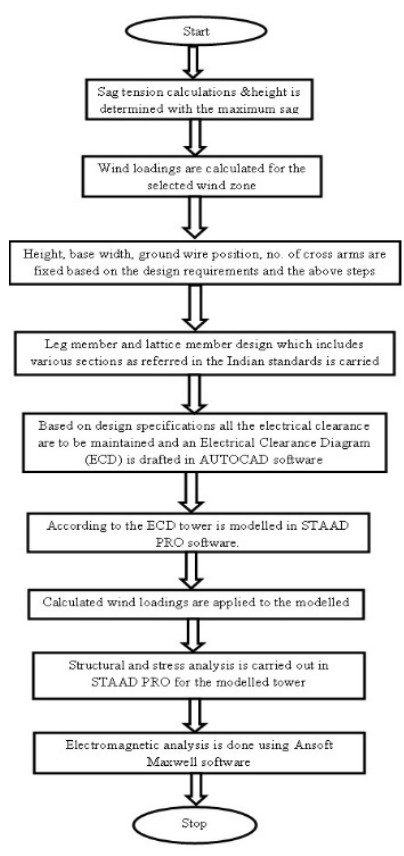

Figure 1. Tower design flowchart.

\subsection{Tower modelling}

After designing a tower and based on its Electrical Clearance Diagram (ECD) the tower is modelled in STAAD.PRO software and the corresponding calculated loads are applied to the members.

\subsection{Stress Analysis}

The accurate stress analysis for a transmission tower includes calculation of the total forces in each member of the tower with various combination of loads externally applied plus the self-weight of structure. All values are calculated according to permissible values. The flowchart given in the following Figure 1 gives the basic design process for any transmission tower.

\section{Proposed MVMCT Design}

The conductor configuration is considered to reduce the electro-magnetic fields and also to optimize the design. The combination of delta and horizontal for $220 \mathrm{kV} \& 33$ $\mathrm{kV}$ with a defined phase sequence which is $[\mathrm{ABC}-\mathrm{ABC}]$, [ABC-CAB], [ABC-ABC] for $400 \mathrm{kV}, 220 \mathrm{kV}, 33 \mathrm{kV}$ respectively is selected to reduce the overall electromagnetic fields.

\subsection{EMF Analysis}

The Electro Magnetic Field analysis is done using finite element analysis in Ansoft Maxwell software. The accuracy of finite element analysis depends on the mesh topology. The mesh is a significant feature of any finite element model. The Magneto static field limits confinement are given in ICNIRP and those limits are considered for the proposed design. Electrostatic field ought to be under $5 \mathrm{kV} / \mathrm{m}$ at the edge of the right of way. The magnetic field should be less than $100 \mu \mathrm{T}^{10}$. The current carrying capacity considered are $800.4 \mathrm{~A}, 705 \mathrm{~A}, 464 \mathrm{~A}$ for $400 \mathrm{kV}, 220 \mathrm{kV}$, $33 \mathrm{kV}$ respectively. Electro-static field relies on voltage and magneto-static field relies on current.

The energy efficient voltage conversion can also be determined in multiple voltage domains ${ }^{11}$.The soil resistivity is also checked for safety purposes in order to avoid back flashover ${ }^{12}$.

\section{Results and Discussion}

A case study has been conducted using the $400 \mathrm{kV} / 220 \mathrm{kV} / 33 \mathrm{kV}$ for the proposed methodology to reduce the right of way by considering three voltages and each voltage level holding two circuits on the same tower. The results obtained are presented in this section. The following Table 1 gives the maximum sag and the corresponding tension values.

Based on all clearances mentioned in Indian standards and the maximum sag value calculated above is used to determine the height of the tower. After determination of height the cross arm lengths are decided and fixed consid- 
ering all the design requirements. The maximum height calculated is $56.2 \mathrm{~m}$. The maximum cross arm length from the center of the tower for $400 \mathrm{kV}$ line is $7.525 \mathrm{~m}$ which is used to determine the ROW width.

The line diagram representing all the cross arms, height of conductors from the ground levels is given in following Figure 2.

Table 1. Sag and Tension

\begin{tabular}{|l|l|l|}
\hline Voltage $(\mathrm{kV})$ & Max. Sag $(\mathrm{m})$ & Tension $(\mathrm{Kg})$ \\
\hline 400 & 4.29 & 2334.80 \\
\hline 220 & 3.96 & 2046.50 \\
\hline 33 & 3.52 & 1385.33 \\
\hline
\end{tabular}

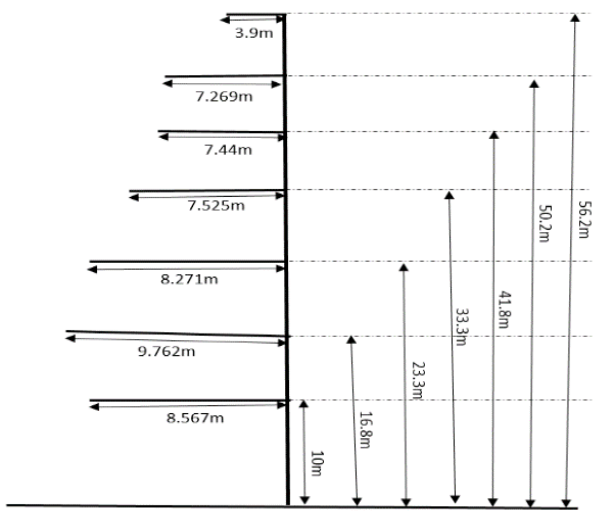

Figure 2. Line diagram representing geometry of the tower.

The following Figure 3 gives the basic structural details for the MVMCT. This Table 2 includes all the structural design data for MVMCT.

Table 2. Tower geometry

\begin{tabular}{|l|l|}
\hline Height & 56.2 Meters \\
\hline Conductor configuration & vertical, delta, horizontal \\
ACSR MOOSE (twin), ZEBRA, \\
PANTHER
\end{tabular}

\begin{tabular}{|l|l|}
\hline Base width & 7 Meters \\
\hline Type & Narrow base \\
\hline Angle of line deviation & $0^{0}-2^{0}$ \\
Span & $200 \mathrm{~m}$ \\
\hline Tower shape & Barrel \\
\hline
\end{tabular}

Electrical Clearance Diagram has been drafted in AutoCAD software based on the clearances and basic design requirements and is given in the following figure. Design parameters are given in Table 3.

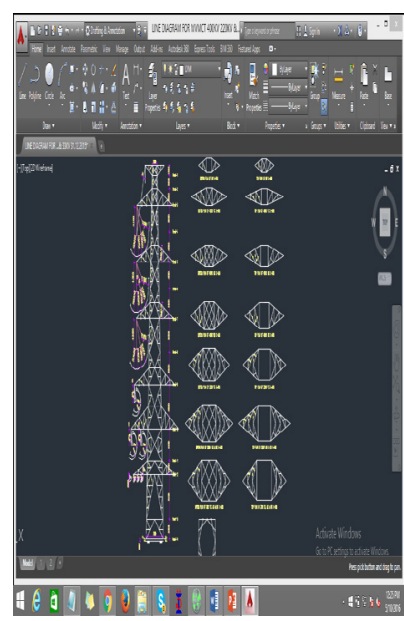

Figure 3. Electrical clearance diagram.

Table 3. Design parameters

\begin{tabular}{|l|l|}
\hline Wind zone & 5 \\
\hline Reliability level & 2 \\
\hline Terrain category & 2 \\
\hline Basic wind speed & $50 \mathrm{~m} / \mathrm{s}$ \\
\hline Max. Temperature & $85^{0} \mathrm{C}$ \\
\hline Min. Temperature & $0^{0} \mathrm{C}$ \\
\hline Cross arm shape & Pointed \\
\hline Ground wire cross arm & Inverted \\
\hline Type of the tower & Suspension \\
\hline Bracing pattern & $\begin{array}{l}\text { X-pattern, Portal pattern (only } \\
\text { for lower panels) }\end{array}$ \\
\hline
\end{tabular}

With the help of the Electrical clearance diagram the tower is modelled in STAAD.PRO software in 3 dimensional coordinate system. The following Figure 4 shows 
the isometric view of the designed MVMCT in STAAD. PRO software.

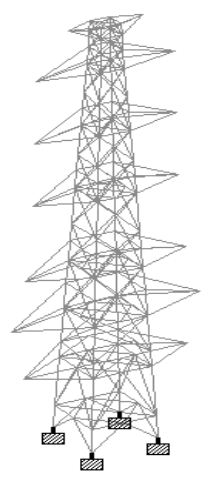

Figure 4. Isometric view of MVMCT.

The following Figure 5 shows the screenshots of various loads that are applied to the designed tower. The loads include transverse, longitudinal and vertical loads. All loads are applied to all the members according to Indian standards which are inbuilt in the software. The tower should withstand all the calculated loads and this is justified by stress analysis in the software.

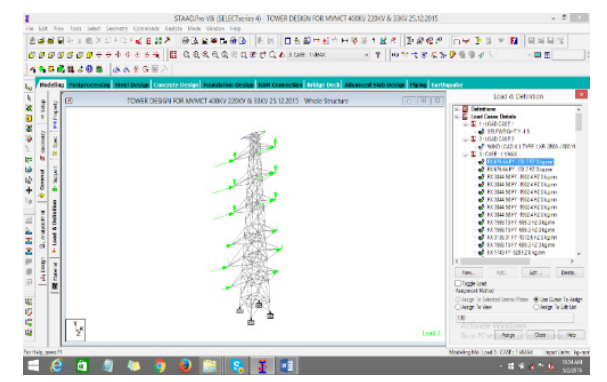

Figure 5. Screenshot of MVMCT with the assigned wind loads.

\section{Stress Analysis of MVMCT}

The stress analysis includes determination of forces in every member of the tower with different load combinations including self-weight of the structure. Different loads are considered for stress analysis in each member of the tower. The loads considered are transverse loads longitudinal load, vertical loads. To meet the values within the permissible limits specified in standards the slenderness ratio should not be beyond the values specified in the following Table 4.
Table 4. Slenderness ratio specified in standards

\begin{tabular}{|c|c|c|}
\hline SL.NO & Slenderness ratio for the design & Ratio \\
\hline 1 & $\begin{array}{l}\text { Leg members and main members in the } \\
\text { cross-arm in compression }\end{array}$ & 150 \\
\hline 2 & Members carrying computed stresses & 200 \\
\hline 3 & $\begin{array}{l}\text { Redundant members and those carrying } \\
\text { nominal stresses }\end{array}$ & 250 \\
\hline 4 & Tension members & 350 \\
\hline
\end{tabular}

The following Figure 6 shows the stress analysis in STAAD.PRO for the proposed MVMCT and also the stresses on all members of the tower are within the permissible limits.

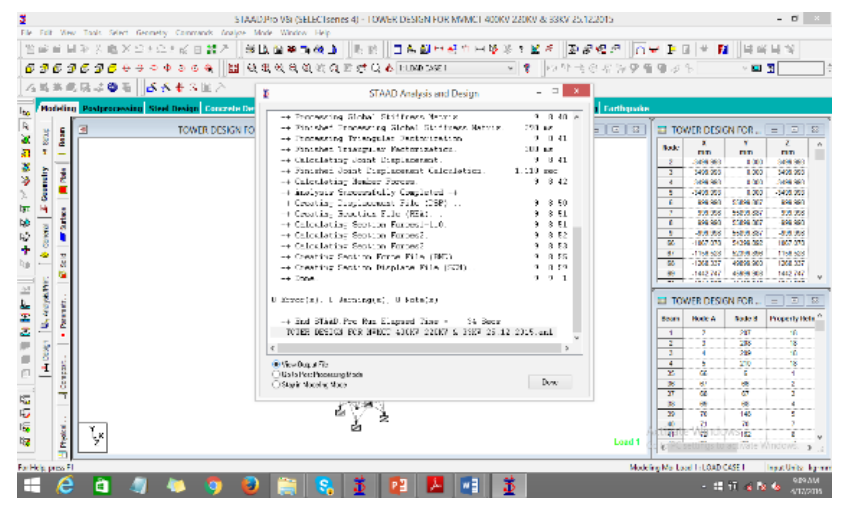

Figure 6. Screenshot of stress analysis in STAAD.PRO.

\section{Discretization of MVMCT for Electromagnetic Analysis}

The input given to the software is simplified into simple problems which is called discretization/mesh conversion and the analysis is carried out for this mesh plot using Maxwells' applications in the Ansoft Maxwell software. The first circles from the top indicate vertical 400 $\mathrm{kV}$ vertical conductor arrangement, next three indicate delta conductor arrangement of $220 \mathrm{kV}$ and the last three indicate horizontal arrangement of conductors of $33 \mathrm{kV}$ respectively. We use different program options which are called solvers in the software for mathematical conversion of the algebraic equations of the physical arrangement of MVMCT. The solvers used are Electro-static, Magnetostatic for the proposed MVMCT. The mesh plot of the MVMCT is given in following Figure 7. 


\section{Electromagnetic Fields Analysis}

The mesh plot generated gives the analysis of fields after complete validation of the inputs. The following Figures 8, 9 represent the electrostatic field overlays and the Magneto-static field overlays around conductors of 400 $\mathrm{kV} / 220 \mathrm{kV} / 33 \mathrm{kV}$ and the fields are in volts/meter \& $\mu \mathrm{T}$ respectively.

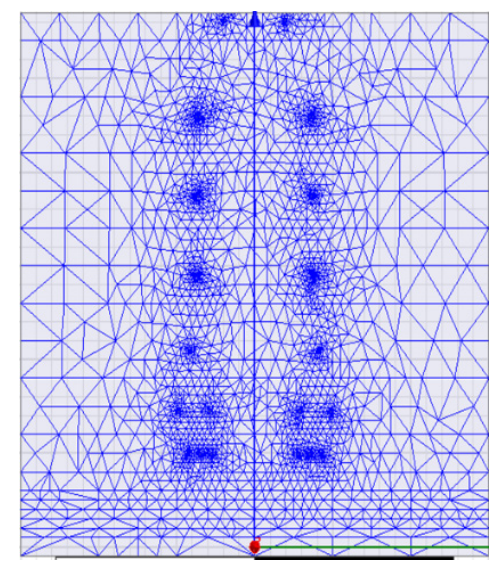

Figure 7. Mesh plot of MVMCT in Ansoft Maxwell.

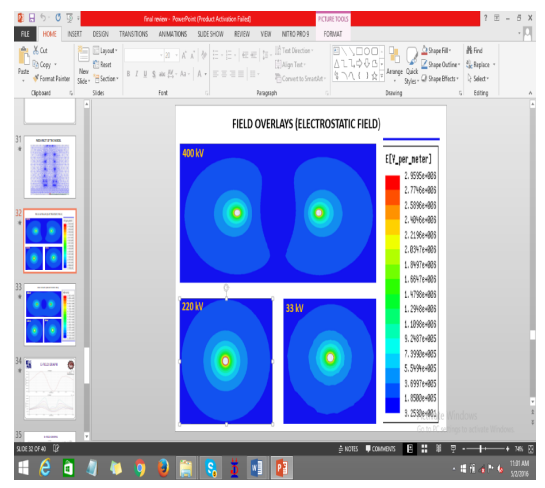

Figure 8. Electro-static field overlays.

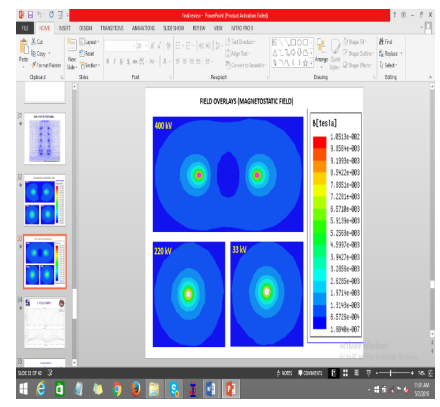

Figure 9. Magneto-static field overlays.

The plots in Figures 10, 11 present electrostatic field curve and magneto-static field curve considered one meter above the ground level and this curve gives the maximum value of electro-static field and magneto-static field respectively.

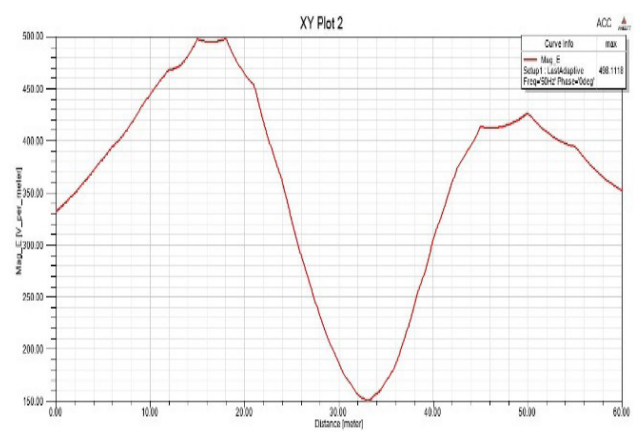

Figure 10. Electro-static field curve.

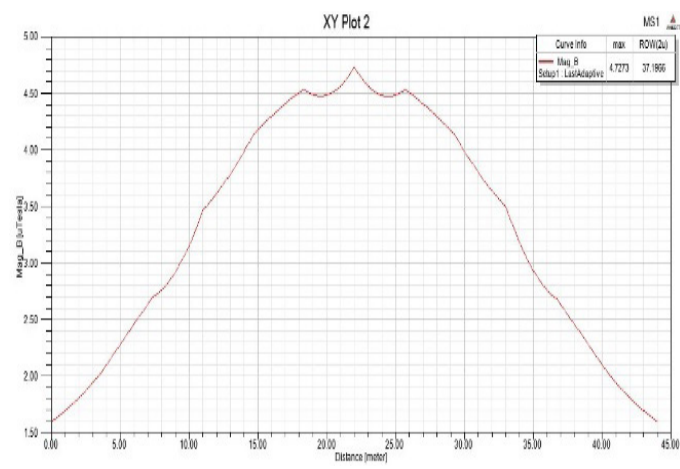

Figure 11. Magneto-static field curve.

The following Table 5 shows that the maximum simulated value is within the prescribed limits given in standards.

Table 5. Electric and magnetic field limits

\begin{tabular}{|c|c|c|c|}
\hline \multirow[t]{2}{*}{ Field } & \multirow{2}{*}{$\begin{array}{l}\text { Specified } \\
\text { (1m above the } \\
\text { ground level) }\end{array}$} & \multicolumn{2}{|c|}{ Simulated Values } \\
\hline & & $\begin{array}{l}\text { Max. } \\
\text { Value }\end{array}$ & $\begin{array}{l}\text { At the Edge } \\
\text { of ROW }\end{array}$ \\
\hline $\begin{array}{l}\text { Electric field } \\
(\mathrm{kV} / \mathrm{m})\end{array}$ & 5 & 0.498 & 0.440 \\
\hline $\begin{array}{l}\text { Magnetic field } \\
(\mu \mathrm{T})\end{array}$ & 100 & 4.7273 & 2 \\
\hline
\end{tabular}

\section{Tower Economics}

When compared to conventional towers MVMCT gives huge savings in cost. The following Table 6 shows the difference between MVMCT and combination of three individual towers. All cost calculations are considered for $100 \mathrm{Km}$ line with a design span of $200 \mathrm{~m}$. The cost per 
square meter is taken as 100 Rs per square meter. Total towers include $70 \%$ of $\mathrm{A}, 15 \%$ of $\mathrm{B}, 10 \%$ of C, $5 \%$ of D type as per regular consideration of utilities. Types of towers A, B, C\& D are based on deviation angle of the line specified in standards.

Table 6. Cost calculations

\begin{tabular}{|l|l|l|}
\hline & $\begin{array}{l}\text { 3 Individual } \\
\text { Towers }\end{array}$ & MVMCT \\
\hline ROW Width (m) & 98 & 40 \\
\hline Cost of steel (in lakhs) & 45572.59 & 7054.70 \\
\hline Total cost (in lakhs) & 19451.93 & 13048.71 \\
\hline Savings (in lakhs) & 6403.22 & \\
\hline
\end{tabular}

\section{Conclusion}

An innovative method to reduce the ROW width in the design of MVMCT has been proposed in this paper. A case study on MVMCT containing three different voltages such as $400 \mathrm{kV} / 220 \mathrm{kV} / 33 \mathrm{kV}$ has been done and is demonstrated that the proposed design offers technically superior method and is also cost effective. ROW width is reduced to 40 (from 48) meters when compared to conventional broad base towers which leads to a huge cost savings when a transmission line is considered. MVMCT also improves the transmission capacity. The EMF's are also in the specified limits with in the ROW. All stresses are within the permissible limits. Cost savings can be around $30-50 \%$ when ROW is constrained Thus MVMCT with narrow base may become a headway in India both on economic issues and minimization of legal issues with respect to the land.

\section{References}

1. Dezelak K, Stumberger G, Jakl F. Arrangements of overhead power line conductors related to the electromagnetic field limits. Modern Electric Power Systems Wroclaw, Poland; 2010.
2. Raghavendra T. Computer aided analysis and structural optimization of transmission line tower. International Journal of Advanced Engineering Technology; 2012.

3. Sakthivel S, Sanjeevir. Analysis and design of multi circuit transmission line tower. International Journal of Emerging Technology in CSE. 2015; 13(1):1-6.

4. Liu W. Research on electromagnetic character of $500 / 220 \mathrm{kv}$ mixed-voltage quadruple-circuit transmission line. 2015; 9(7):686-93.

5. Feng G, Wang Y, Zhang B. Study on electromagnetic environment of multi-circuit transmission lines on same tower. Joint International Conference on Power System Technology and IEEE Power India Conference, New Delhi; 2008. p. $1-5$.

6. Punse GS. Analysis and design of transmission tower. International Journal of Multidisciplinary Educational Research. 2014; 4(1):1-23.

7. IS 802 (Part $1 /$ Sec $1 \& \operatorname{Sec} 2$ ):1995. Code of practice for use of structural steel in overhead transmission line towers. Part 1Materials, Loads and Permissible Stresses, Section 1: Materials and Loads.

8. Manual on Transmission Line Towers. Central Board of Irrigation and Power, New Delhi; 1994.

9. IS 802 (Part 2/Sec 2): IS: 802 (Part 1/ Sec 2:1992. Use of structural steel in overhead transmission line tower - code of practice.

10. ICNIRP (The International Commission On Non-Ionizing Radiation Protection), guidelines for limiting exposure to time-varying electric, magnetic and electromagnetic fields (up to 300Ghz). Health Physics. 1998; 74(4):1262-76.

11. Sinthuja S, Kumar JH, Manoharan N. Energy efficient voltage conversion range of multiple level shifter design in multi voltage domain. Indian Journal of Science and Technology. 2014 Oct; 7(S6):82-6.

12. Rao IK, Rukmini MSS, Das RP, Rao PT, Manikanta G. Design of frequency domain induced polarization equipment having optimized frequency of signal transmission. Indian Journal of Science and Technology. 2016 Feb; 9(6):1-5. DOI: $10.17485 / \mathrm{ijst} / 2016 / \mathrm{v} 9 \mathrm{i} 6 / 85032$. 